\title{
Rethinking Feelings: An fMRI Study of the Cognitive Regulation of Emotion
}

\author{
Kevin N. Ochsner ${ }^{1}$, Silvia A. Bunge ${ }^{2}$, James J. Gross ${ }^{1}$, and \\ John D. E. Gabrieli ${ }^{1}$
}

\begin{abstract}
The ability to cognitively regulate emotional responses to aversive events is important for mental and physical health. Little is known, however, about neural bases of the cognitive control of emotion. The present study employed functional magnetic resonance imaging to examine the neural systems used to reappraise highly negative scenes in unemotional terms. Reappraisal of highly negative scenes reduced subjective
\end{abstract}

\section{INTRODUCTION}

We humans are extraordinarily adaptable creatures. Drawing upon a vast array of coping skills, we can successfully manage adversity in even the most trying of circumstances. One of the most remarkable of these skills was described by Shakespeare's (1998/1623, p. 216) Hamlet, who observed, "there is nothing either good or bad, but thinking makes it so." Although Hamlet himself failed to capitalize on this insight, his message is clear: We can change the way we feel by changing the way we think, thereby lessening the emotional consequences of an otherwise distressing experience.

The cognitive transformation of emotional experience has been termed "reappraisal." In both experimental and individual-difference studies, reappraising an aversive event in unemotional terms reduces negative affect with few of the physiological, cognitive, or social costs associated with other emotion-regulatory strategies, such as the suppression of emotion-expressive behavior (Jackson, Malmstadt, Larson, \& Davidson, 2000; Richards \& Gross, 2000; Gross, 1998, 2002; Gross \& John, in press). The mechanisms that mediate such reappraisals, however, are not yet understood. The goal of the present study was to use functional magnetic resonance imaging (fMRI) to elucidate the neural bases of reappraisal.

Although little prior work has directly examined the neural systems involved in the cognitive control of emotion, we expected that it would involve processing dynamics similar to those in implicated in other well-

${ }^{1}$ Stanford University, ${ }^{2}$ Massachusetts Institute of Technology

(C) 2002 Massachusetts Institute of Technology experience of negative affect. Neural correlates of reappraisal were increased activation of the lateral and medial prefrontal regions and decreased activation of the amygdala and medial orbito-frontal cortex. These findings support the hypothesis that prefrontal cortex is involved in constructing reappraisal strategies that can modulate activity in multiple emotionprocessing systems.

studied forms of cognitive control. In general, cognitive control is thought to involve interactions between regions of lateral (LPFC) and medial prefrontal cortex (MPFC) that implement control processes and subcortical and posterior cortical regions that encode and represent specific kinds of information (Miller \& Cohen, 2001; Knight, Staines, Swick, \& Chao, 1999; Smith \& Jonides, 1999). By increasing or decreasing activation of particular representations, prefrontal regions enable one to selectively attend to and maintain goal-relevant information in mind and resist interference (Miller \& Cohen, 2001; Knight et al., 1999; Smith \& Jonides, 1999). Based on these cognitive neuroscience models, as well as process models of emotion and emotion regulation (Gross, 2002; Ochsner \& Feldman Barrett, 2001), we hypothesized that comparable interactions between cognitive control and emotion-processing systems would underlie reappraisal.

With respect to cognitive-processing systems, we hypothesized that reappraisal would involve three processes implemented by lateral and medial frontal cortices. The first is the active generation of a strategy for cognitively reframing an emotional event in unemotional terms, and keeping that strategy in mind as long as the eliciting conditions endure. In neuropsychological (Barcelo \& Knight, 2002; Stuss, Eskes, \& Foster, 1994), functional imaging (Cabeza \& Nyberg, 2000; Smith \& Jonides, 1999; Barch et al., 1997), and electrophysiological (Barcelo, Suwazono, \& Knight, 2000; Nielsen-Bohlman \& Knight, 1999) studies, these functions have been associated with working memory processes localized in the LPFC. The second process may monitor interference between top-down reappraisals that 
neutralize affect and bottom-up evaluations that continue to generate an affective response, signaling the need for reappraisal to continue. In a variety of tasks involving response conflict (Barch et al., 2001; van Veen, Cohen, Botvinick, Stenger, \& Carter, 2001; Phelps, Hyder, Blamire, \& Shulman, 1997) or overriding prepotent response tendencies (Carter et al., 2000; Peterson et al., 1999), these functions have been associated with the dorsal anterior cingulate cortex (for reviews, see Botvinick, Braver, Barch, Carter, \& Cohen, 2001; Bush, Luu, \& Posner, 2000). The third process involves reevaluating the relationship between internal (experiential or physiological) states and external stimuli, which may be used to monitor changes in one's emotional state during reappraisal. The dorsal regions of the MPFC are activated when making attributions about one's own (Paradiso et al., 1999; Lane, Fink, Chau, \& Dolan 1997) or another person's (Gallagher et al., 2000; Happe et al., 1996) emotional state as well as during viewing of emotional films (Beauregard et al., 1998; Lane, Reiman, Ahern, Schwartz, \& Davidson, 1997; Reiman et al., 1997) or photos (Lane, Reiman, Bradley, et al., 1997). Importantly, activation of the medial frontal cortex when anticipating painful shock (Chua, Krams, Toni, Passingham, \& Dolan, 1999; Hsieh, StoneElander, \& Ingvar, 1999; Ploghaus et al., 1999) may be inversely correlated with the experience of anxiety (Simpson et al., 2000), suggesting its importance for regulatory control (cf. Morgan \& LeDoux, 1995).

With respect to emotion-processing systems, we hypothesized that reappraisal would modulate the processes involved in evaluating a stimulus as affectively significant. Many theories of emotion posit that at least two types of evaluative processing are involved in emotion generation (Lazarus, 1991; for a review, see Scherer, Schorr, \& Johnstone, 2001). One type is important for determining whether a stimulus is affectively relevant and may be relatively automatic, whereas a second type is important for evaluating contextual meaning and the appropriateness of possible responses (Scherer et al., 2001; Lazarus, 1991). Evidence suggests that two highly interconnected brain structures (Cavada, Company, Tejedor, Cruz-Rizzolo, \& Reinoso-Suarez, 2000), the amygdala and medial orbital frontal cortex (MOFC), are associated with these two types of emotion processing (Ochsner \& Feldman Barrett, 2001; LeDoux, 2000; Bechara, Damasio, Damasio, \& Lee, 1999). On one hand, the amygdala is important for the preattentive detection and recognition of affectively salient stimuli (Anderson \& Phelps, 2001; Morris, Ohman, \& Dolan, 1999; Whalen et al., 1998), learning and generating physiological and behavioral responses to them (LeDoux, 2000; Bechara et al., 1999), and modulating their consolidation into declarative memory (Hamann, Ely, Grafton, \& Kilts, 1999; Cahill, Babinsky, Markowitsch, \& McGaugh, 1995). On the other hand, the MOFC is important for representing the pleasant or unpleasant affective value

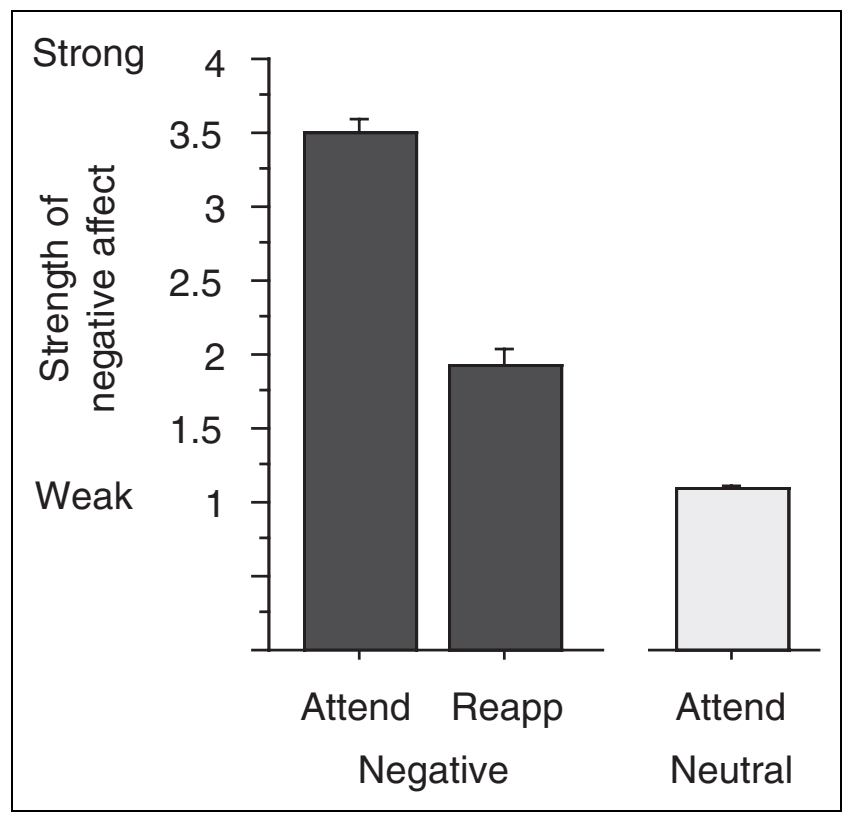

Figure 1. Average negative ratings made during scanning for the most negative photos (the third of photos that elicited the most negative affect for a given participant). Negative affect was strong on Attend trials and decreased significantly on Reappraise (Reapp) trials $(p<.01)$. When participants attended to their feelings towards neutral photos, the negative affect elicited was significantly weaker than for all other trial types (both $p<$ at least .01).

of a stimulus (Kawasaki et al., 2001; O'Doherty, Kringelbach, Rolls, Hornak, \& Andrews, 2001; Davidson \& Irwin, 1999; Rolls, 1999; Elliott, Frith, \& Dolan, 1997) in a flexible format that is sensitive to momentary changes in social and motivational context (Ochsner \& Feldman Barrett, 2001; Bechara, Damasio, \& Damasio, 2000; Rolls, 1999). Together, the amygdala and the MOFC differentially encode and represent the affective properties of stimuli (Bechara et al., 1999; Rolls, 1999), and we sought to determine whether reappraisal modulates activity in the MOFC, amygdala, or both.

To test these hypotheses, we adapted an experimental procedure used to study regulation of the fearpotentiated startle eyeblink response (Jackson et al., 2000). In that study, participants viewed aversive photos and were instructed either to increase, maintain, or decrease (postexperimental debriefing suggested that participants reappraised) their emotional reactions. Startle eyeblink magnitude (which was used as an indicator of the relative strength of an emotional reaction across trial types) increased, remained constant, or decreased according to the regulatory strategy being employed. This result suggests that participants can successfully regulate their emotional responses on a trial-by-trial basis. To isolate the processes related to the cognitive control of emotion, we needed to compare reappraisal to another condition that draws on processes invoked by reappraisal, but are not related to the regulation of affect per se. Because we hypothesized that reappraisal involves both attention to and 
awareness of one's emotional state, as well as regulatory processes directed towards altering it (Gross, 1998), we employed two conditions: On "Attend trials," participants were asked to let themselves respond emotionally to each photo by being aware of their feelings without trying to alter them. On "Reappraise trials," participants were asked to interpret photos so that they no longer felt negative in response to them. Because both Attend and Reappraise trials involve attention to emotion, regions more active when reappraising than attending were thought to reflect processes used to exert cognitive control. In contrast, regions more active for Attend than Reappraise trials were thought to be important for emotion processing that would be deactivated by reappraisal.

Each trial began with a 4-sec presentation of a negative or neutral photo, during which participants were instructed simply to view the stimulus on the screen. This interval was intended to provide time for participants to apprehend complex scenes and to allow an emotional response to be generated that participants then would be asked to regulate. The word Attend (for negative or neutral photos) or Reappraise (negative photos only) then appeared beneath the photo and participants followed this instruction for $4 \mathrm{sec}$, at which time the photo disappeared from the screen. Because we were interested in the processes used to actively reappraise an affective event as it unfolds, we focused our analyses on this portion of each trial. During this portion of the trial, we predicted that (a) Reappraise trials would result in greater lateral prefrontal activation than Attend trials and (b) that Attend trials would show greater activation of the MOFC and the amygdala than would Reappraise trials. For approximately three more seconds, participants could continue attending to or reappraising any feelings that lingered after presentation of the photo. A rating scale then appeared, which participants used to rate the strength of their current negative affect and which we used to verify that that reappraisal had successfully reduced negative feelings as compared to Attend trials. Finally, participants were instructed to relax for 4 sec before the next trial began.

\section{RESULTS}

The experimental procedure included a measure that allowed us to segregate and analyze separately the trials on which participants experienced their strongest emotional responses without biasing the initial perception of photos during scanning. In a post-scanning session,
Figure 2. Group-averaged brain activations when reappraising or attending to feelings in response to the most negative photos. Two contrasts are shown: The Attend > Reappraise (shown in red) contrast shows regions important for emotion processing that are significantly modulated by reappraisal and the Reappraise $>$ Attend (shown in green) contrast shows regions significantly activated when exerting cognitive control over emotion activated by reappraisal. Top and bottom brain images on the right show regions of the left dorsal and ventral LPFC associated with cognitive control that were activated by reappraisal. Right side and bottom left brain images show reappraisal-related modulation of a region of left MOFC associated with representing the affective properties of stimuli.

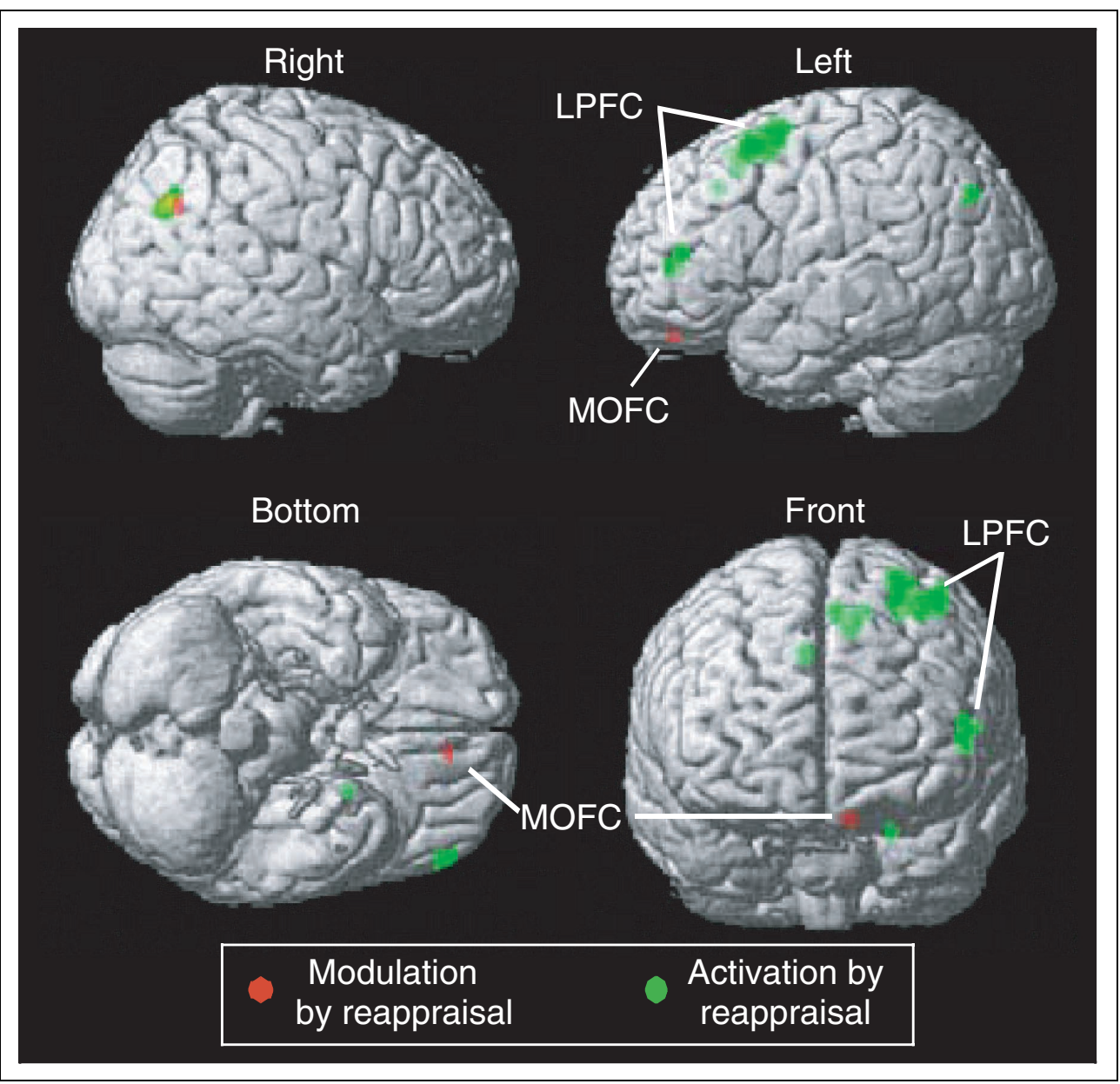


Table 1. Group Activations for Reappraise $>$ Attend Contrast

\begin{tabular}{|c|c|c|c|c|c|c|}
\hline \multirow[b]{2}{*}{ Region of Activation } & \multirow[b]{2}{*}{ Brodmann's Area } & \multicolumn{3}{|c|}{ Coordinates } & \multirow[b]{2}{*}{ Z Score } & \multirow[b]{2}{*}{ Volume $\left(\mathrm{mm}^{3}\right)$} \\
\hline & & $x$ & $y$ & $z$ & & \\
\hline \multicolumn{7}{|l|}{ Group Contrast } \\
\hline Superior frontal gyrus & L6 & -36 & 14 & 58 & 3.90 & 2736 \\
\hline Superior frontal gyrus & $\mathrm{L} 6 / 8$ & -24 & 6 & 64 & 3.71 & (L) \\
\hline Middle frontal gyrus & L6/8 & -24 & 10 & 56 & 3.68 & (L) \\
\hline Middle frontal gyrus & L6/8 & -40 & 2 & 60 & 3.60 & 416 \\
\hline \multirow[t]{2}{*}{ Inferior frontal gyrus } & L46 & -54 & 42 & 12 & 3.79 & 736 \\
\hline & $\mathrm{L} 44 / 10$ & -48 & 46 & 4 & 3.31 & $(\mathrm{~L})$ \\
\hline \multirow[t]{2}{*}{ Dorsomedial prefrontal cortex } & 8 & -12 & 18 & 54 & 3.47 & 1040 \\
\hline & 8 & -4 & 20 & 54 & 3.39 & \\
\hline Dorsomedial prefrontal cortex & $8 / 32$ & 8 & 28 & 40 & 3.88 & 224 \\
\hline Temporal pole & 28 & -22 & 4 & -26 & 4.21 & 128 \\
\hline Lateral occipital cortex & 19 & -38 & -74 & 40 & 4.23 & 240 \\
\hline Supramarginal gyrus & $\mathrm{R} 39 / 40$ & 54 & -70 & 30 & 4.23 & 688 \\
\hline \multicolumn{7}{|c|}{ Positive Correlation between Activation and Drop in Negative Affect When Reappraising } \\
\hline Anterior cingulate & $\mathrm{R} 24$ & 6 & 14 & 32 & 4.67 & 88 \\
\hline Supramarginal gyrus & $\mathrm{R} 40$ & 54 & -48 & 34 & 4.05 & 40 \\
\hline
\end{tabular}

Clusters of 5 or more contiguous voxels whose global maxima meet a $t$ threshold of $3.09, p<.001$ uncorrected, are reported. Local maxima for these clusters are denoted with (L). Coordinates are in MNI space.

participants viewed each negative photo a second time and rated the strength of their initial affective response (i.e., when they first viewed it, before they had attended or reappraised). These ratings were used to identify the third of the negative photos of each trial type that were rated most negative by each participant. As has been found in prior studies (Canli, Zhao, Brewer, Gabrieli, \& Cahill, 2000), preliminary analyses indicated that reliable activation of emotion-processing systems was observed only for these most negative images. Given that the goal of this study was to examine the modulation of these systems by reappraisal, the analyses reported here focused only on these trial types.

\section{Subjective Reports of Negative Affect}

\section{Segregating Most Negative Photos}

Post-scan ratings of affective response indicated that the third of photos rated most negative $(M=3.77)$ elicited significantly greater negative affect than the moderately negative $(M=2.99)$ or least negative $(M=1.93)$ third of photos (all differ $p<.01$ ). Affect ratings for negative photos selected from Attend as compared to Reappraise trials did not differ significantly at any level of affect (all $p>.16$ ). The fact that retrospective ratings of negative affect were equivalent on Attend and Reappraise trials suggests that in-scan reappraisals did not bias post-scan emotional responses to photos. However, because these ratings were provided retrospectively, it is important to provide independent evidence that post-test ratings can be correlated with a participant's initial affective response to a stimulus (Ochsner \& Schacter, in press). A separate pilot behavioral study was conducted to provide such evidence. Eight female participants rated their affective response to photos an average of 3 days before completing a test session that procedurally was equivalent to the scanning session used in the present study. They then completed post-test retrospective ratings of the affective response they had to each photo when it was viewed during the test session. Results indicated that pre- and post-test ratings of negative affect were highly correlated for all trial types and all levels of negative photos (i.e, most, moderately, or least negative, all $p<.01$ ), which suggests that post-test ratings can provide a reliable index of one's initial affective response to a photo.

\section{Success of Reappraisal}

Ratings made during scanning showed that overall, moderate, and least negative photos elicited less negative affect than the most negative photos (both $p<.01$ ), 
which is consistent with post-test reports of initial affective response. Significantly, reappraisal was successful for the most negative photos: The average ratings of the strength of negative affect were high on Attend trials $(M=3.48)$ and were significantly lower on Reappraise trials $^{1}[M=1.90, t(14)=17.41, p<.01]$ (Figure 1). Reappraisal was potent enough that affect was diminished to that experienced when attending to the least negative photos $(p>.5)$. Although negative affect was not as great as that reported for most negative photos, ratings for both the moderately negative and least negative photos showed a similar pattern of successful reappraisal [moderate: Attend $M=2.75$, Reappraise $M=1.52, t(14)=7.66, p<.01$; least: Attend $M=2.05$,
Reappraise $M=1.43, t(14)=4.27, p<.01]$. However, comparisons with affect reported on Attend-neutral trials $(M=1.08)$ showed that in no case did reappraisal entirely eliminate negative affect $(p<.01$ for all comparisons).

\section{Manipulation Check}

In a pre-scan training session, participants were instructed to reappraise photos during scanning by generating an interpretation of, or story about, each photo that would explain apparently negative events in a less negative way. To verify that participants had, in fact, reappraised in this manner, during the post-scan rating
Figure 3. Region of right anterior cingulate cortex (MNI coordinates: 6, 14, 32) identified in a regression analysis as showing a significant correlation between increasing activation and decreasing negative affect on Reappraise as compared to Attend trials with negative photos. Activation is shown on SPM99 canonical T1 image.

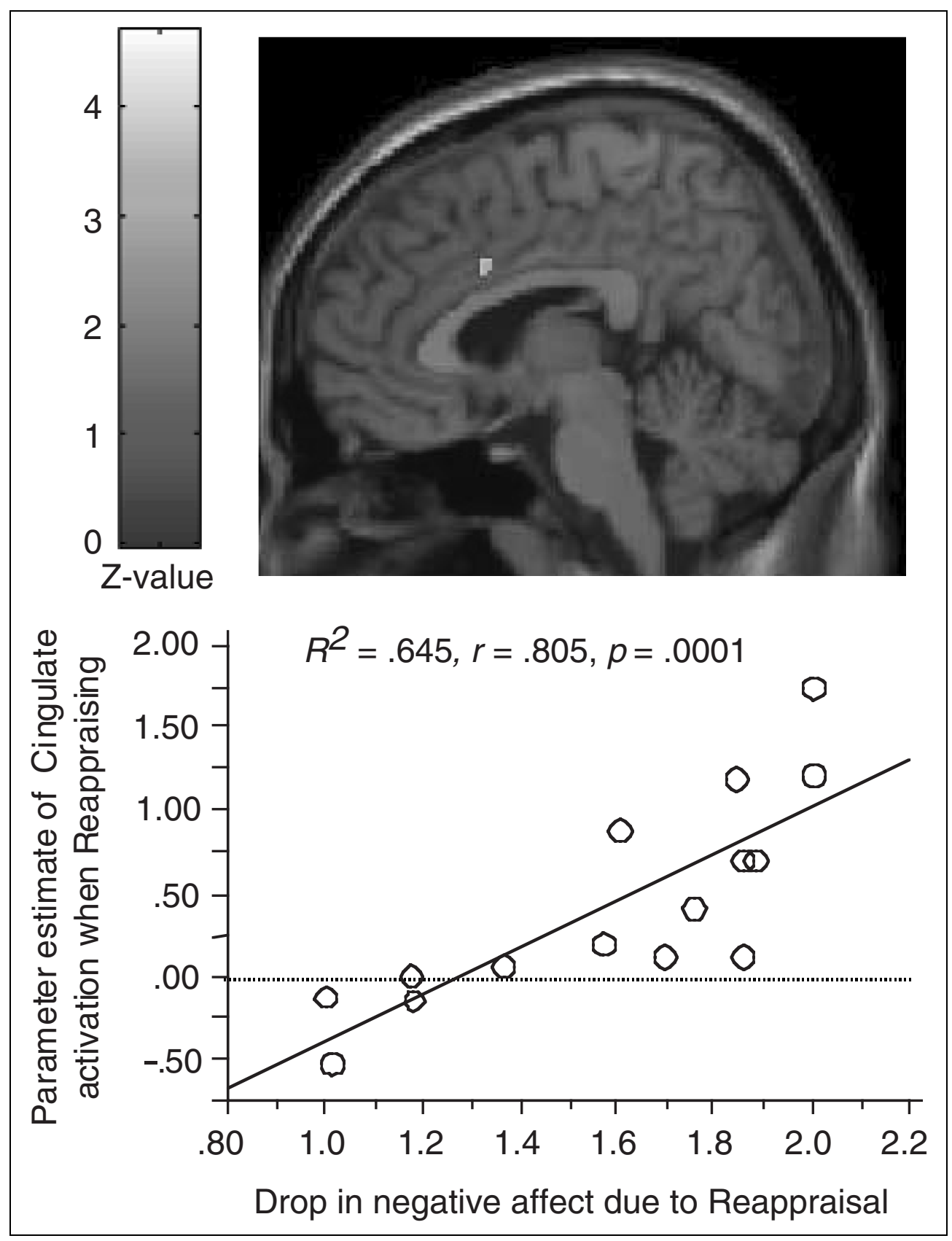


Table 2. Group Activations for Attend > Reappraise Contrast

\begin{tabular}{|c|c|c|c|c|c|c|}
\hline \multirow[b]{2}{*}{ Region of Activation } & \multirow[b]{2}{*}{ Brodmann's Area } & \multicolumn{3}{|c|}{ Coordinates } & \multirow[b]{2}{*}{ Z Score } & \multirow[b]{2}{*}{ Volume $\left(\mathrm{mm}^{3}\right)$} \\
\hline & & $x$ & $y$ & $z$ & & \\
\hline Medial orbito-frontal cortex & L11 & -6 & 44 & -22 & 4.17 & 112 \\
\hline Posterior insula & L13 & -44 & -16 & 2 & 3.84 & 240 \\
\hline Inferior parietal cortex & $\mathrm{R} 39 / 19$ & 38 & -64 & 34 & 3.86 & 640 \\
\hline Medial occipital cortex & R19 & 22 & -76 & 40 & 3.46 & 240 \\
\hline Amygdala & $\mathrm{R}$ & 16 & -12 & -20 & $2.88^{*}$ & 112 \\
\hline
\end{tabular}

Clusters of 5 or more contiguous voxels whose global maxima meet a $t$ threshold of $3.09, p<.001$ uncorrected, are reported. Local maxima for these clusters are denoted with (L). Coordinates are in MNI space.

${ }^{*} T=2.98, p<.005$.

session participants also were asked to indicate for each photo whether they had reinterpreted the photo (as instructed) or had used some other type of reappraisal strategy. Compliance with instructions was very high: On less than $4 \%$ of trials with highly negative photos did participants report using another type of strategy.

\section{Brain Imaging Results}

\section{Activation by Reappraisal}

Reappraisal-sensitive regions were identified by greater activation in response to the most negative photos on Reappraise than on Attend trials. Consistent with predictions, significantly activated regions included the dorsal and ventral regions of the left LPFC, as well as the dorsal MPFC (Figure 2, Table 1). Additional reappraisal-related activations were observed in left temporal pole, right supramarginal gyrus, and left lateral occipital cortex (Figure 2, Table 1). Contrary to expectations, activation of the cingulate cortex was not observed.

Cingulate involvement in reappraisal was revealed, however, in an SPM99 regression analysis used to identify regions for which level of brain activation across participants correlated significantly with reappraisal success. An index of reappraisal success was computed for each participant by subtracting the mean level of negative affect reported on Reappraise trials from that reported on Attend trials when highly negative images were shown. Larger difference scores thus corresponded to a greater decrease in negative affect, which is indicative of a more effective reappraisal. At a threshold of $p<.001$ (uncorrected), activity in no brain regions was negatively correlated, and in only two regions was positively correlated, with reappraisal success such that greater activation predicted greater decreases in negative affect. These two regions were located in the right anterior cingulate and right supramarginal gyrus (Figure 3, Table 1). To more precisely characterize these correlations, mean parameter estimates of the response increase when reappraising as compared to attending were correlated with reappraisal success. These correla- tions were highly significant both for the foci in the anterior cingulate $\left(R^{2}=.649, r=.805, p=.0001\right)$ and the supramarginal gyrus $\left(R^{2}=.570, r=.755, p<.0006\right)$.

\section{Modulation by Reappraisal}

Emotion-sensitive regions modulated by reappraisal were identified by greater activation in response to the most negative photos on Attend than on Reappraise trials. Activation was observed in a region of left MOFC (Figure 2, Table 2). Additional regions of activation were found in the left posterior insula, right medial occipital cortex, and right inferior parietal cortex (Figure 2, Table $2)$. The amygdala, an a priori region-of-interest (ROI), was not significantly activated at a map-wise statistical threshold of $p<.001$. However, significant activation was observed in the right amygdala at a more liberal threshold $(p<.005)$ (Figure 4$)$. This finding was

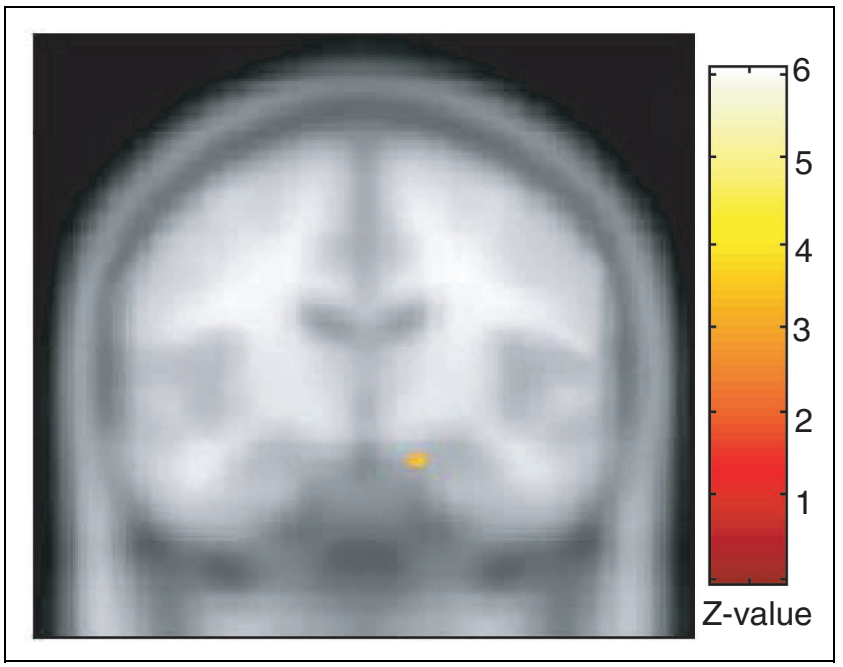

Figure 4. Coronal image showing the group-averaged cluster of activation in right amygdala for the Attend $>$ Reappraise contrast for trials with the most negative photos $(p<.005)$. The focus is centered on MNI coordinates $(16,-12,-20)$. Activation is shown on groupaveraged anatomy. 
confirmed by the results of a planned ROI analysis in which parameter estimates that model the amplitude of the fMRI response were extracted from structurally defined ROIs (see, e.g., Figure 4). For the right amygdala, this analysis revealed a significantly greater amplitude of response on Attend than Reappraise trials ( $p<.025$, one-tailed for planned comparison). The response to most negative photos on Reappraise trials was not significantly different from the response to neutral photos on Attend trials $[t(14)<1, p>.5]$
(Figure 5). No significant differences in response were shown across trial types for the left amygdala ROI [all $t(14)<1, p>.5$ ].

To further characterize the relationships between reappraisal-related increases and decreases in brain activation, mean parameter estimates across trial types were contrasted for a set of functionally defined ROIs: The first was the region of MOFC identified by the Attend $>$ Reappraise contrast, and the others were regions of the LPFC activated by the Reappraise $>$ Attend contrast
Figure 5. ROI analyses. (a) Functionally or structurally defined ROIs and (b) group mean parameter estimates $(M \pm S E M)$ for each ROI on Attend and Reappraise (Reapp) trials using negative photos, and Attend trials using neutral photos. Note that the negative images contributing to this analysis were identified as the third of negative images that were given the most negative rating by each participant (see Methods and Results). Top row: A functionally defined ROI within the left ventral LPFC (BA 46/10) activated by Reappraise $>$ Attend contrast, centered on MNI coordinates $(-54,42,12)$ and shown on group-averaged anatomy. This is the only prefrontal region whose activation during reappraisal was inversely correlated with activation in emotion-processing regions (shown in Figure 6). Middle row: A functionally defined ROI within left MOFC (BA 11) identified by the Attend $>$ Reappraise contrast, centered on MNI coordinates $(-6,46$,

-20) and shown on groupaveraged anatomy. Bottom row: Sample structurally defined ROI for the right amygdala from a single subject centered on MNI coordinates $(24,-7,-15)$. Ventral LPFC activation on Reappraise-most negative trials was significantly greater than on Attend-most negative trials $(p<.025$, one-tailed), whereas the MOFC and amygdala showed the opposite pattern (both $p<.025$, one-tailed).

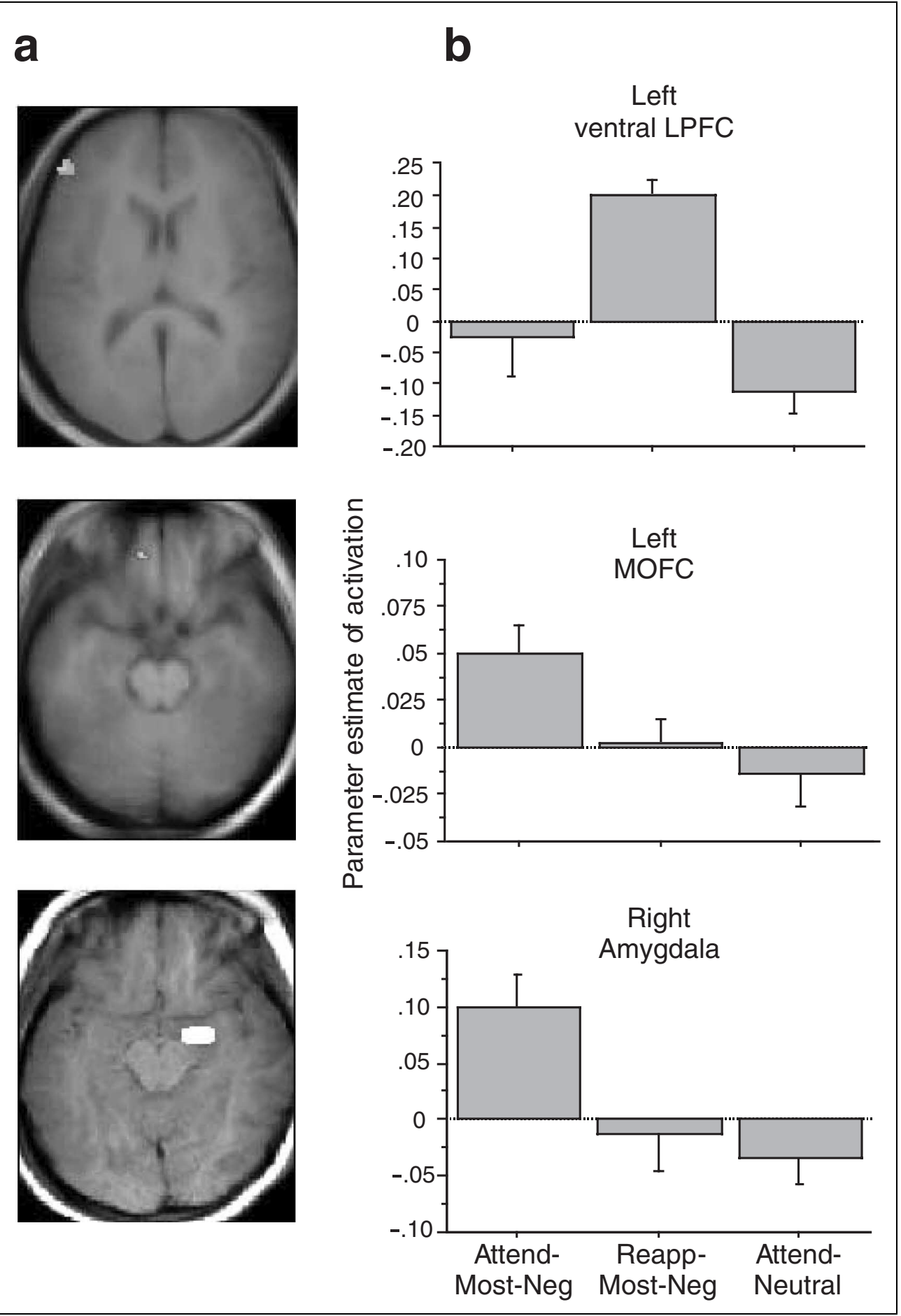


(Table 1). These analyses indicated that MOFC exhibited greater activation to most negative photos on Attend than on Reappraise trials, whereas activated regions of the LPFC exhibited precisely the opposite pattern $(p<$ .025 , one-tailed for planned comparisons). For one of the activated prefrontal regions - the ventral LPFC - the reappraisal-related increase in brain activation was correlated across participants with the reappraisal-related decrease in amygdala activation $(r=-.677, p<.004$; for all other regions, $p>$.19). Ventral LPFC activation also was negatively correlated with MOFC activation, albeit to a lesser extent $(r=-.494, p<.06)$ (Figure 6). Activation on Attend-neutral trials was not significantly different from either activation on Attend-most negative trials in this ventral prefrontal region $[t(14)<1.2, p>.24]$ or

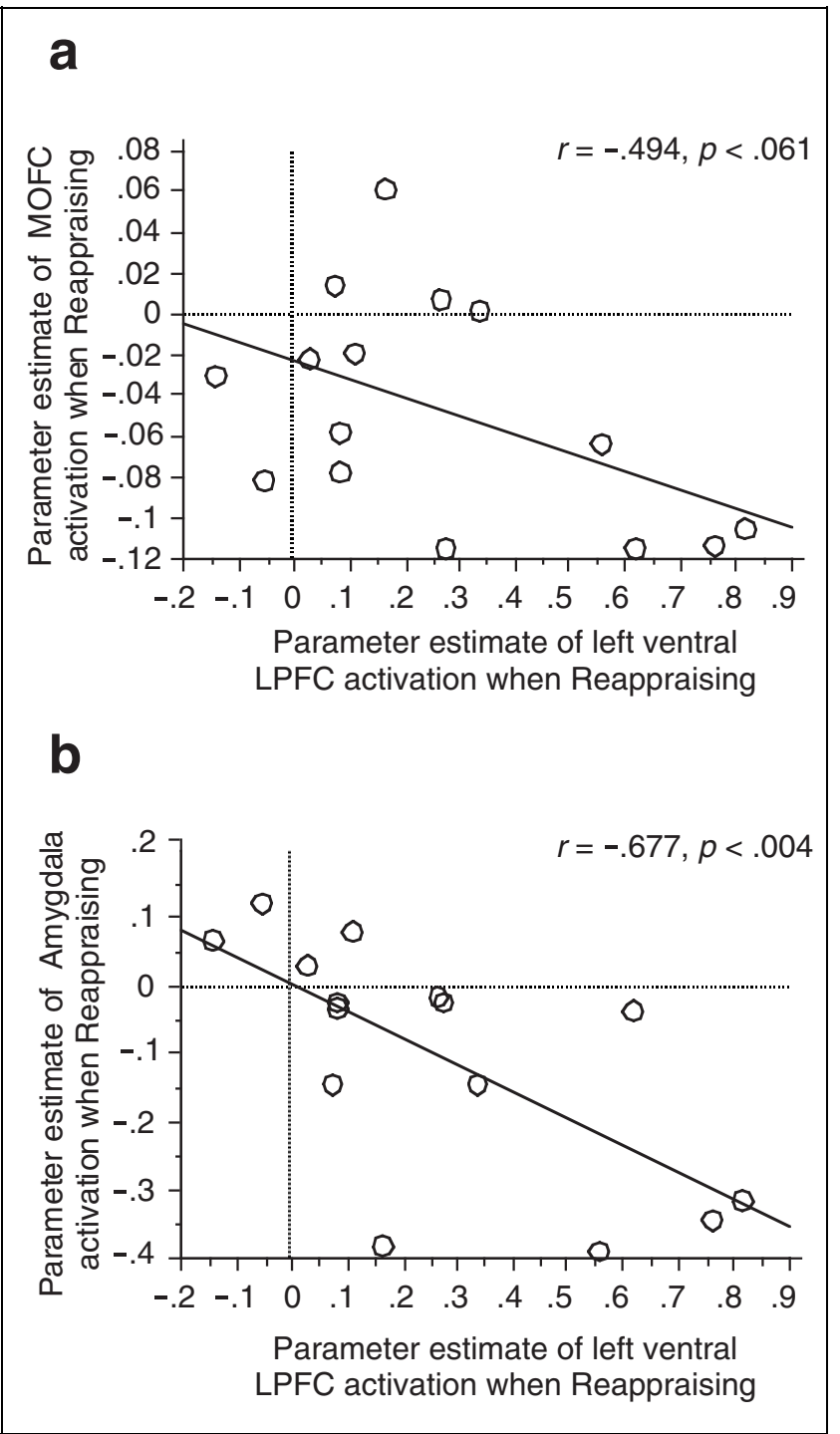

Figure 6. Correlations between reappraisal-induced changes in parameter estimates of activation for the functional and structural ROIs shown in Figure 5. During reappraisal, increases in response in the ventral LPFC (a) correlated with decreases in response in the amygdala and (b) to a lesser degree correlated with decreases in response in the MOFC. from activity on Reappraise-most negative trials in MOFC and amygdala [both $t(14)<1, p>$.5] (Figure 5).

\section{DISCUSSION}

This study is one of the first to use functional imaging to draw inferences about the neural bases of the cognitive control of emotion. Behaviorally, reappraisal of negative photos successfully diminished negative affect. Neural correlates of effective reappraisal were (1) activation in the regions of the LPFC and MPFC essential for working memory, cognitive control (Miller \& Cohen, 2001; Knight et al., 1999; Smith \& Jonides, 1999), and selfmonitoring (Gusnard, Akbudak, Shulman, \& Raichle, 2001) and (2) decreased activation in two regions involved in emotion processing, the MOFC and the amygdala (Adolphs, 2001; Ochsner \& Feldman Barrett, 2001; Bechara et al., 1999; Davidson \& Irwin, 1999; Rolls, 1999). In addition, the magnitude of ventral LPFC activation during reappraisal was inversely correlated with activation in both emotion-processing regions. Taken together, these findings provide the first evidence that reappraisal may modulate emotion processes implemented in the amygdala and MOFC that are involved in the evaluating the affective salience and contextual relevance of a stimulus (Ochsner \& Feldman Barrett, 2001; Phelps et al., 2001; Bechara et al., 2000; LeDoux, 2000; Bechara et al., 1999; Rolls, 1999).

\section{Cognitive Processes Supporting Reappraisal}

The particular regions of the LPFC and MPFC activated by reappraisal are similar to the regions commonly activated across working memory and response-selection tasks that involve maintaining information in awareness and resisting interference from competing inputs (Cabeza \& Nyberg, 1999; Smith \& Jonides, 1999; Courtney, Petit, Maisog, Ungerleider, \& Haxby, 1998; Petit, Courtney, Ungerleider, \& Haxby, 1998; Alexander, Delong, \& Strick, 1996). These similarities suggest that an overlapping set of prefrontal regions support the cognitive regulation of feelings and thoughts (Miller \& Cohen, 2001; Ochsner \& Feldman Barrett, 2001; Davidson \& Irwin, 1999; Knight et al., 1999; Smith \& Jonides, 1999).

The finding that activation of the ventral LPFC was inversely correlated with the activation of the amygdala and the MOFC suggests that this region may play a direct part in modulating emotion processing, perhaps related to the role of ventral frontal regions in interference control and behavioral inhibition more generally (Miller \& Cohen, 2001; Smith \& Jonides, 1999). It is notable, however, that other prefrontal regions were even more strongly activated by reappraisal, although these activations did not correlate significantly with activity in emotion-processing regions. Although this initial study was not designed to determine the precise 
contributions to the reappraisal process made by each region, they may mediate processes necessary for, but not directly related to, successful reappraisal. For example, dorsomedial prefrontal cortex was the region most strongly activated by reappraisal. This region has been associated with emotional awareness (Lane, 2000; Lane, et al., 1997), drawing inferences about one's own (Paradiso et al., 1999) or others' (Gallagher et al., 2000; Happe et al., 1996) emotional states, and self-related processing (Gusnard et al., 2001) more generally. The need to monitor and evaluate the self-relevance of emotional stimuli could be important whenever one reappraises (Scherer et al., 2001; Lazarus, 1991) and may be used to regulate anxiety in anticipation of aversive events (Simpson et al., 2000). Similarly, the superior prefrontal regions have been associated with spatial working memory and control of eye movements (Smith \& Jonides, 1999; Courtney et al., 1998), both of which could be needed for analyzing and reinterpreting perceptual inputs during reappraisal.

We also hypothesized that the anterior cingulate cortex would be involved in reappraisal. Although cingulate activation was not observed in the group contrast of Reappraise and Attend trials, there was, across participants, a positive correlation between cingulate activation and effective reappraisal. The anterior cingulate cortex is thought to be important for monitoring ongoing processing and evaluating the need for cognitive control (e.g., Botvinick et al., 2001), and it might be expected that successful reappraisal would depend upon the use of this process to monitor for conflicts between initial emotional appraisals and cognitively restructured reappraisals. In the present study, cingulate activation may therefore reflect active monitoring that enhanced the cognitive transformation of an aversive experience.

\section{Emotion Processes Modulated by Reappraisal}

The observation that reappraisal can influence brain systems implicated in emotion processing may have significance for contemporary appraisal theories of emotion (for a review, see Scherer et al., 2001). It has been clear that reappraisal diminishes negative emotion experience and negative emotion-expressive behavior (Gross, 1998), but theorists have not specified the types of emotion processing that might be influenced by reappraisal. Although the present study was not designed to determine which specific emotion-processing functions attributable to the amygdala and MOFC are modulated by reappraisal, modulation of these two brain structures is consistent with the idea that reappraisal can influence processes involved in evaluating the affective salience of a stimulus (Anderson \& Phelps, 2001; Morris et al., 1999; Whalen et al., 1998), as well those important for evaluating the salience of that stimulus in the context of current situational or personal goals (Kawasaki et al., 2001; Ochsner \& Feldman Barrett,
2001; O’Doherty et al., 2001; Bechara et al., 2000; Davidson \& Irwin, 1999; Rolls, 1999; Elliott et al., 1997).

Further work will be needed to determine which specific aspects of amygdala and OFC functioning can be modulated by reappraisal. On one hand, the appraisal function of the amygdala often is characterized as automatic (e.g., LeDoux, 2000; Morris et al., 1999). In the present study, it likely that reappraisal did not modulate this early amygdala response, which is thought to depend upon subcortical inputs from the senses. Instead, reappraisal may have influenced a more sustained response that may depend (as discussed below) on cortical inputs and is more amenable to control by cognitive processes. It will be important to determine whether and how reappraisal could influence the early automatic response as well. On the other hand, the MOFC often is characterized as serving a regulatory function, ${ }^{2}$ as evidenced, for example, by its roles in decision-making involving risky choices (e.g., Bechara et al., 2000) and extinction of conditioned fear responses (e.g., Morgan et al., 1995; see, however, footnote 2). On our view, the cognitive processes supporting reappraisal, as well as the emotional processes supporting context-sensitive evaluation, may both exert regulatory effects, albeit in different ways. Whereas the evaluation processes supported by OFC may support the selection of appropriate, and the transient suppression of inappropriate, affective responses, the reappraisal processes supported by lateral and medial prefrontal regions may be important for modulating these evaluation processes themselves. By down-regulating multiple types of evaluation processes, reappraisal may shift from an emotional to an unemotional mode of stimulus analysis.

Further work will also be needed to determine exactly how prefrontal regions modulate the amygdala and MOFC during reappraisal. In the present study, we observed an inverse correlation between lateral prefrontal and amygdala activation during reappraisal, although these two structures share few direct connections. One route by which the LPFC could influence the amygdala is via the MOFC, which has reciprocal connections with both regions (Cavada et al., 2000). By directly modulating representations of the affective significance of a stimulus in the MOFC, activation in the LPFC could blunt processing in the amygdala indirectly. This seems somewhat unlikely, however, because the correlation between the LPFC and the MOFC activity was not as strong as the correlation between LPFC and amygdala activity (which could be due, in part, to signal loss in MOFC). A second possible route involves prefrontal modulation of posterior perceptual and semantic inputs to the amygdala from the occipital and parietal regions (de Fockert, Rees, Frith, \& Lavine, 2001; Miller \& Cohen, 2001; Knight et al., 1999; Smith \& Jonides, 1999). Reappraising the affective significance of images in working memory may reorganize these inputs so that the amygdala and the MOFC no longer register the presence 
of an aversive stimulus. This view is supported by the fact that reappraisal modulated activation in the lateral occipital cortex, a region associated with visual object processing, and the supramarginal gyrus, an inferior parietal region associated with attentional selection and storage of information held in working memory (Cabeza \& Nyberg, 1999; Culham \& Kanwisher, 2001; Smith \& Jonides, 1999). Future research may help determine which account is correct.

\section{The Nature of Emotion Regulation}

The present study provides insight into the processes supporting reappraisal. However, a number of additional steps will be necessary to develop a more complete framework for understanding the cognitive and affective mechanisms of emotion and emotion regulation more generally (Ochsner \& Feldman Barrett, 2001). In particular, the present research raises at least two important questions about the nature of emotion regulation.

The first question concerns the way in which emotion processing might be modulated differently by cognitive reappraisal as compared to other forms of emotion regulation. A pair of studies have examined attentional influences on emotion processing and found that enhanced amygdala responses to fearful faces did not change as attention to a fear stimulus decreased (Anderson et al., 2001; Vuilleumier, Armony, Driver, \& Dolen, 2001). These results contrast with the present finding that attempts to cognitively transform feelings can modulate amygdala activity. A handful of other studies have examined the influence on amygdala processing of cognitive judgments that involve explicit evaluation of the emotional properties of faces as compared to evaluation of stimulus dimensions unrelated to emotion, such as gender or age. Results have been mixed, with some studies finding that evaluative judgments diminish amygdala activation (Hariri, Bookheimer, \& Mazziotta, 2000; Liberzon et al., 2000) and others finding the opposite (Winston, Strange, O’Doherty, \& Dolan, 2002; Critchley et al., 2000). Although the precise relevance of these judgments to emotion regulation is not clear, some of the discrepant findings could be attributable to a differential dependence of some evaluative judgments on processes involved in reappraisal. More generally, the present results may be difficult to directly relate to these studies because of the differences in the stimuli employed and the responses they evoke. Whereas the present study used stimuli that elicit relatively strong responses that induce changes in emotional experience, the words and faces employed in other studies elicit weaker responses overall and only rarely alter experience (Ochsner \& Feldman Barrett, 2001; Davidson \& Irwin, 1999). Future work may serve to clarify the precise ways in which different types of regulation modulate different aspects of emotion (Ochsner \& Feldman Barrett, 2001; cf. Gray, in press).
A second question concerns the lateralization of activations and deactivations related to reappraisal and emotion processing, respectively. One possibility is that these findings are related to properties of the particular regulatory processes involved in the present study. Left lateralization of reappraisal-related prefrontal activations may, for example, reflect a common verbal component of reappraisal strategies employed by participants, who typically reported mentally talking themselves through their reappraisals. ${ }^{3}$ Left prefrontal regions have been implicated in interference tasks involving verbal stimuli (e.g., Bunge, Ochsner, Desmond, Glover, \& Gabrieli, 2001; Macdonald, Cohen, Stenger, \& Carter, 2000; D’Esposito, Postle, Jonides, \& Smith, 1999; Jonides, Smith, Marshuetz, Koeppe, \& Rueter-Lorenz, 1998), which suggests that this region may represent verbal reappraisal strategies and help resolve interference with competing negative evaluations generated by the perception of aversive stimuli. Were one to examine other types of reappraisal or other emotion-regulation strategies that do not share this interpretive verbal component (e.g., those involving attentional deployment, as discussed above, or the suppression of expressive emotional behavior; Gross, 1998), it is possible that activation of the right prefrontal systems would be observed. This hypothesis is supported by a study showing that regulating responses to a sexually arousing film clip by viewing them from a detached third-person perspective activated right PFC and deactivated structures related to sexual arousal, including the hypothalamus and the amygdala (Beauregard, Levesque, \& Bourgouin, 2001). In this context, the deactivation of the right amygdala and the left MOFC may reflect stimulus (as compared to verbally)driven processing of affective information by the amygdala (Phelps et al., 2001; Morris et al., 1999), and the observation that the right amygdala and the left orbitofrontal cortex activity may be coupled during sensory processing of aversive stimuli (Zald \& Pardo, 1997).

A second possible explanation for lateralized activations relates to findings associating negative affect with the right hemisphere and positive affect with the left hemisphere (e.g., Canli, Desmond, Zhao, Glover, \& Gabrieli, 1998; see Davidson \& Irwin, 1999, for a review). Thus, right amygdala deactivation could reflect downregulation of systems that generate negative appraisals whereas left PFC activation could reflect engagement of systems supporting positivizing reappraisals. This interpretation is consistent with the finding that relatively greater resting activation of the left than the right PFC is correlated with resistance to depression, which may in turn reflect baseline differences in the ability to represent cognitive control strategies used to down-regulate emotion processing (Davidson, Putnam, \& Larson, 2000). Consistent with this view, studies of resting brain metabolism in individuals with depression or obsessivecompulsive disorder-who may be unable to effectively 
represent these strategies-have shown hypoactivation of the prefrontal regions coupled with hyperactivation of the amygdala and/or the orbito-frontal cortex that normalizes with effective treatment (Davidson et al., 2000; Brody et al., 1999; Saxena et al., 1999).

\section{Conclusions}

The aim of the present study was to use information about brain function to draw inferences about the mechanisms supporting one type of cognitive control of emotion. As such, it represents one example of a growing trend towards using neuroscience methods to address questions that traditionally have been of interest to social and personality psychologists (Ochsner \& Lieberman, 2001). Although findings suggest that cognitive reappraisal can modulate multiple types of emotion processing, questions remain about the functional significance of observed frontal and amygdala activations, their relation to other forms of regulation, and their relevance to clinical populations. As future work addresses these questions, we may be able to better connect Hamlet's timeless observation that thinking can make things good or bad with an increased understanding of how the brain makes this possible.

\section{METHODS}

\section{Participants}

Fifteen healthy right-handed female volunteers ${ }^{4}$ recruited from Stanford University and the surrounding community (ages 18-30, $M=21.9$ ) gave informed consent and were paid $\$ 50$ for their participation.

\section{Task}

On the basis of normative ratings, two sets of 38 negative color photos and one set of 38 neutral color photos were selected from the International Affective Picture System (Lang, Greenwald, Bradley, \& Hamm, 1993). The task design was adapted from Jackson et al. (2000). At the beginning of each trial, a photo (subtending approximately $20 \times 20^{\circ}$ of visual angle) appeared in the center of a black screen for $4 \mathrm{sec}$ with the instruction VIEW printed in white underneath. Many photos depicted complex scenes, and during this viewing period participants were instructed to view the photo, understand its content, and allow themselves to experience/feel any emotional response it might elicit. The photo remained on the screen for an additional $4 \mathrm{sec}$ with an instruction either to ATTEND or REAPPRAISE replacing the instruction to VIEW. On Attend trials, either a negative or a neutral photo was shown and participants were instructed to attend to and be aware of, but not to try to alter, any feelings elicited by it. On Reappraise trials, a negative photo was shown and participants were instructed to reinterpret the photo so that it no longer elicited a negative response. The 4-sec epoch during which participants were attending or reappraising negative photos is the subject of the functional imaging analyses reported in the present study. The photo then disappeared and, for $3.1 \mathrm{sec}$, participants could continue attending to, or reappraising, any feelings that lingered after its presentation. A four-point scale ( 1 = "weak" to $4=$ "strong") for rating the strength of current negative affect then was presented for $3 \mathrm{sec}$, and participants indicated how they felt currently. Finally, an instruction to RELAX appeared in the center of the screen for $5 \mathrm{sec}$. A 900-msec interval separated each trial.

\section{Testing Procedure}

One to three days before scanning, participants received extensive instruction in reappraisal. Pilot testing suggested reappraisal was commonly accomplished by generating an interpretation of, or a story about, each photo that would explain apparently negative events in a less negative way (e.g., women depicted crying outside of a church could be described as attending a wedding instead of a funeral). No single type of reinterpretation was universally applicable to all photos, which was expected given that individuals must generate contextappropriate reappraisals in everyday life. To strike a balance between generalizability and experimental control, we instructed participants to select the reinterpretation that was most effective for each photo. Training began by asking participants to spontaneously generate reappraisals of sample photos. After appropriate coaching and shaping by the researcher to ensure that participants could reinterpret photos quickly and effectively, the training ended with the completion of 18 practice trials. It was stressed that when asked to reappraise, participants should neither look away (unless necessary; no subjects reported that it was) nor distract themselves with irrelevant and/or positive thoughts.

During scanning, participants completed one hundred and fourteen 20-sec trials over six separate scans. Each scan included approximately equal numbers of each trial type, and trial order was counterbalanced across scans so that every trial type followed every other with equal probability. Assignment of photos to trial types and scans was counterbalanced across participants. Psyscope was used to control stimulus presentation and response collection. Upon completion of scanning, participants viewed all the negative photos they had seen in the scanner and indicated the strength of their initial negative reaction to each one (i.e., during the viewing period, before attending, or reappraising). These ratings were used to identify the trials that involved the photos rated most negatively by each participant. To verify that participants had, in fact, reappraised, for each photo they were asked to indicate whether they had generated an alternative 
interpretation or whether they had used some other types of reappraisal strategy.

\section{Data Acquisition}

Whole-brain imaging data were acquired on a 3-T MRI Signa LX Horizon Echospeed scanner (GE Medical Systems, 8.3_m4 systems revision). T2-weighted flowcompensated spin-echo anatomical images (TR, 2000 msec; TE, $85 \mathrm{msec}$ ) were acquired in 16 contiguous 7-mm axial slices. Functional images were acquired with the same slice prescription using a T2*-sensitive gradient-echo spiral pulse sequence (Glover \& Lai, 1998) (TE, 30 msec; TR, $1000 \mathrm{msec}$; two interleaves; flip angle $60^{\circ}$, field of view, $24 \mathrm{~cm} ; 64 \times 64$ data acquisition matrix).

\section{Data Analysis}

Functional images were motion-corrected and normalized to a standard template brain using SPM99 (Wellcome Department of Cognitive Neurology). Normalized images were interpolated to $2 \times 2 \times 4$-mm voxels and spatially smoothed with a Gaussian filter $(6 \mathrm{~mm}$ full width half maximum). Low-frequency noise and differences in global signal between participants were removed. Single participants' data were analyzed with a fixed-effects model (Friston, Jezzard, \& Turner, 1994) and group data were analyzed using a random-effects model (Holmes \& Friston, 1998). Effects were modeled using a box-car convolved with a canonical hemodynamic response function for the 4-sec trial epoch during which participants reappraised or attended while a photo was on the screen. An anatomically defined gray matter mask was created and explicitly specified during analysis. This ensured that statistical analysis was performed in all brain regions, including those where signal may be low due to susceptibility artifacts. For the group analysis, functional images were averaged to create a single image of mean activation per trial type and participant. To identify regions recruited across participants that were activated or relatively deactivated by reappraisal, one-sample $t$ tests were performed on these average images to create a series of $\operatorname{SPM}\{Z\}$ maps depicting differences in brain activation between trial types. To identify regions for which the level of reappraisal-related activation across participants was correlated with the reappraisal-related decreases in negative affect, a simple regression analysis was performed on the average images for the Reappraise $>$ Attend contrast. Except as noted below, for group contrasts and regression analysis, a voxel-level threshold of $p<.001$ uncorrected for multiple comparisons $(t=3.09)$ was used. An extent threshold of five contiguous voxels was applied to activated clusters meeting the voxel-level threshold. Maxima are reported in MNI305 coordinates, as in SPM99.
To determine whether reappraisal modulated the amygdala's response to negative photos, structurally defined ROIs were drawn around each participant's amygdalae on their in-plane anatomical images (Desmond \& Lim, 1997). Parameter estimates (that model the amplitude of the fMRI response) averaged across all voxels for each ROI were then extracted for Reappraise and Attend trials on which the most negative photos had been presented. For comparison, parameter estimates on Attend neutral trials also were extracted. Planned $t$ tests ( $\alpha=.05$, one-tailed) were used to compare amygdala activation across these three trial types. This analysis also was performed for functionally defined ROIs in regions of a priori interest in the LPFC and MOFC.

\section{Acknowledgments}

This research was supported by NSF grant BCD-0084496, McDonnel-Pew grant 98-23, and grant 5 F32 MH11990-03 from the National Institute of Health. The authors thank Adam Anderson and Kalina Christoff for discussion of relevant issues and comments on earlier drafts of this article.

Reprint requests should be sent to Kevin Ochsner, Department of Psychology, Stanford University, Building 420, Main Quad, Stanford, CA, 94305-2130, USA, or via e-mail: ochsner@psych. stanford.edu.

The data reported in this experiment have been deposited in The fMRI Data Center (http://www.fmridc.org). The accession number is $2-2002-1137 \mathrm{G}$.

\section{Notes}

1. To provide an independent check for bias in participants' subjective reports, and the affect ratings in particular, in a pre-scan session participants were asked to complete the Marlowe-Crowne social desirability scale, which is commonly used as a measure of the tendency to provide responses that would be demanded in an experiment. Overall, scores on this scale were low $(M=13.125)$ and were uncorrelated $(r=-.099, p>.80)$ with reappraisal success (as indexed by the drop in negative affect on reappraise as compared to attend trials). Furthermore, if affect ratings reflected compliance with experimental demand, then ratings might have been expected to drop on reappraise trials to the level of affect reported on aware trials with neutral photos. This did not occur. In fact, ratings on reappraise trials remained sensitive to differences in intensity across photos: ratings on reappraise trials with most negative photos were greater than on reappraise trials for least negative images, which in turn, were still greater than rating on aware neutral trials.

2. Two points concerning the MOFC's role in regulation are relevant here. First, recent studies suggest that the relation of MOFC to extinction is not yet clear. Some animal lesion studies indicate that medial lesions impair extinction (Morgan et al., 1995), others suggest that they do not (Gewirtz, Falls, \& Davis, 1997), whereas others suggest that the impairments may be observed only during some phases of extinction (Quirk, Russo, Barron, \& Leborn, 2000). Although the reasons for these discrepancies await clarification, one possible contributing factor may be that subtle differences in learning contexts lead to differential dependence on context-sensitive appraisal processes associated with MOFC. In some circumstances, when a UCS no longer follows a CS, these appraisal processes 
might be used to try and figure out what action to take next. This decision process might transiently suppress a CR, which research has shown can spontaneously reemerge at a later point. Second, prior work has shown that OFC is involved in modifying associations established in the amygdala (e.g., Rolls, 1999). This modification does not always involve downregulation of amygdala activity, however, and in many cases may involve coactivation of the two structures during emotional learning and evaluation (e.g., Schoenbaum, Chiba, \& Gallagher, 1998). In the case of extinction, OFC activity could also reflect the use of appraisal processes to encode new properties of the stimulus-context relationship. We would suggest, therefore, that these data, along with the results of the present study, are consistent with the conclusion that reappraisal may down-regulate two processing components of a system important for analyzing different kinds of emotion features. Under certain circumstances, these two emotionrelated processors may themselves configure to regulate responses. In the present circumstances, regulatory effects are achieved by shutting them both down. Ultimately, brain systems might best be thought of as performing task nonspecific computations that may play a part in different types of behavior, whether or not that behavior is best described as regulatory.

3. In this regard, it is worth noting that variability introduced by the fact that we did not constrain participants to reappraise photos in exactly the same way (they were free to implement a common cognitive reframing strategy in a whatever manner was appropriate for each photo) could provide a conservative estimate of reappraisal-related prefrontal activations.

4. Only women were studied because women often exhibit stronger emotional responses than men (Kring \& Gordon, 1998), and prior research from our laboratory and others suggested that women respond more strongly and more reliably to the emotional stimuli used in this study (Ito, Cacioppo, \& Lang, 1998).

\section{REFERENCES}

Adolphs, R. (2001). The neurobiology of social cognition. Current Opinion in Neurobiology, 11, 231-239.

Alexander, G. E., Delong, M., \& Strick, P. L. (1996). Parallel organization of functionally segregated circuits linking basal ganglia and cortex. Annual Review of Neuroscience, 9, 357-381.

Anderson, A. K., Panitz, D. A., Ochsner, K. N., Bunge, S. A., Christoff, K., \& Gabrieli, J. D. E. (2001). Examination of attentional modulation of neural responses in affective and neural object processing domains. Society for Neuroscience Abstracts, 120.2 .

Anderson, A. K., \& Phelps, E. A. (2001). Lesions of the human amygdala impair enhanced perception of emotionally salient events. Nature, 411, 305-309.

Barcelo, F., \& Knight, R. T. (2002). Both random and perseverative errors underlie WCST deficits in prefrontal patients. Neuropsychologia, 40, 349-356.

Barcelo, F., Suwazono, S., \& Knight, R. T. (2000). Prefrontal modulation of visual processing in humans. Nature Neuroscience, 3, 399-403.

Barch, D. M., Braver, T. S., Akbudak, E., Conturo, T., Ollinger, J., \& Snyder, A. (2001). Anterior cingulate cortex and response conflict: Effects of response modality and processing domain. Cerebral Cortex, 11, 837-848.

Barch, D. M., Braver, T. S., Nystrom, L. E., Forman, S. D., Noll, D. C., \& Cohen, J. D. (1997). Dissociating working memory from task difficulty in human prefrontal cortex. Neuropsychologia, 35, 1373-1380.
Beauregard, M., Leroux, J. M., Bergman, S., Arzoumanian, Y., Beaudoin, G., Bourgouin, P., \& Stip, E. (1998). The functional neuroanatomy of major depression: An fMRI study using an emotional activation paradigm. NeuroReport, 9, 3253-3258.

Beauregard, M., Levesque, J., \& Bourgouin, P. (2001). Neural correlates of conscious self-regulation of emotion. Journal of Neuroscience, 21, RC165.

Bechara, A., Damasio, H., \& Damasio, A. R. (2000). Emotion, decision making and the orbitofrontal cortex. Cerebral Cortex, 10, 295-307.

Bechara, A., Damasio, H., Damasio, A. R., \& Lee, G. P. (1999). Different contributions of the human amygdala and ventromedial prefrontal cortex to decision-making. Journal of Neuroscience, 19, 5473-5481.

Botvinick, M. M., Braver, T. S., Barch, D. M., Carter, C. S., \& Cohen, J. D. (2001). Conflict monitoring and cognitive control. Psychology Review, 108, 624-652.

Brody, A. L., Saxena, S., Silverman, D. H., Alborzian, S., Fairbanks, L. A., Phelps, M. E., Huang, S. C., Wu, H. M., Maidment, K., \& Baxter, L. R., Jr. (1999). Brain metabolic changes in major depressive disorder from pre- to posttreatment with paroxetine. Psychiatry Research, 91, 127-139.

Bunge, S. A., Ochsner, K. N., Desmond, J. E., Glover, G. H., \& Gabrieli, J. D. E. (2001). Prefrontal regions involved in keeping information in and out of mind. Brain, 124, 2074-2086.

Bush, G., Luu, P., \& Posner, M. I. (2000). Cognitive and emotional influences in anterior cingulate cortex. Trends in Cognitive Sciences, 4, 215-222.

Cabeza, R., \& Nyberg, L. (2000). Imaging cognition: II. An empirical review of 275 PET and fMRI studies. Journal of Cognitive Neuroscience, 12, 1-47.

Cahill, L., Babinsky, R., Markowitsch, H. J., \& McGaugh, J. L. (1995). The amygdala and emotional memory. Nature, 377, 295-296.

Canli, T., Desmond, J. E., Zhao, Z., Glover, G., \& Gabrieli, J. D. (1998). Hemispheric asymmetry for emotional stimuli detected with fMRI. NeuroReport, 9, 3233-3239.

Canli, T., Zhao, Z., Brewer, J., Gabrieli, J. D. E., \& Cahill, L. (2000). Event-related activation in the human amygdala associates with later memory for individual emotional experience. Journal of Neuroscience, 20, RC99.

Carter, C. S., Macdonald, A. M., Botvinick, M., Ross, L. L., Stenger, V. A., Noll, D., \& Cohen, J. D. (2000). Parsing executive processes: Strategic vs. evaluative functions of the anterior cingulate cortex. Proceedings of the National Academy of Sciences, U.S.A., 97, 1944-1948.

Cavada, C., Company, T., Tejedor, J., Cruz-Rizzolo, R. J., \& Reinoso-Suarez, F. (2000). The anatomical connections of the macaque monkey orbitofrontal cortex. A review. Cerebral Cortex, 10, 220-242.

Chua, P., Krams, M., Toni, I., Passingham, R., \& Dolan, R. (1999). A functional anatomy of anticipatory anxiety. Neuroimage, 9, 563-571.

Courtney, S. M., Petit, L., Maisog, J. M., Ungerleider, L. G., \& Haxby, J. V. (1998). An area specialized for spatial working memory in human frontal cortex. Science, 279, 1347-1351.

Critchley, H., Daly, E., Phillips, M., Brammer, M., Bullmore, E., Williams, S., Van Amelsvoort, T., Robertson, D., David, A., \& Murphy, D. (2000). Explicit and implicit neural mechanisms for processing of social information from facial expressions: A functional magnetic resonance imaging study. Human Brain Mapping, 9, 93-105.

Culham, J. C., \& Kanwisher, N. G. (2001). Neuroimaging of cognitive functions in human parietal cortex. Current Opinion in Neurobiology, 11, 157-163.

Davidson, R. J., \& Irwin, W. (1999). The functional 
neuroanatomy of emotion and affective style. Trends in Cognitive Sciences, 3, 11-21.

Davidson, R. J., Putnam, K. M., \& Larson, C. L. (2000). Dysfunction in the neural circuitry of emotion regulationa possible prelude to violence. Science, 289, 591-594.

de Fockert, J. W., Rees, G., Frith, C. D., \& Lavie, N. (2001). The role of working memory in visual selective attention. Science, 291, 1803-1806.

Desmond, J. E., \& Lim, K. O. (1997). On- and offline Talairach registration for structural and functional MRI studies. Human Brain Mapping, 5, 58-73.

D'Esposito, M., Postle, B. R., Jonides, J., \& Smith, E. E. (1999). The neural substrate and temporal dynamics of interference effects in working memory as revealed by event-related functional MRI. Proceedings of the National Academy of Sciences, U.S.A., 96, 7514-7519.

Elliott, R., Frith, C. D., \& Dolan, R. J. (1997). Differential neural response to positive and negative feedback in planning and guessing tasks. Neuropsychologia, 35.

Friston, K. J., Jezzard, P., \& Turner, R. (1994). Analysis of functional MRI time-series. Human Brain Mapping, 1, $153-171$

Gallagher, H. L., Happe, F., Brunswick, N., Fletcher, P. C., Frith, U., \& Frith, C. D. (2000). Reading the mind in cartoons and stories: An fMRI study of 'theory of mind' in verbal and nonverbal tasks. Neuropsychologia, 38, 11-21.

Gewirtz, J. C., Falls, W. A., \& Davis, M. (1997). Normal conditioned inhibition and extinction of freezing and fear-potentiated startle following electrolytic lesions of medial prefrontal cortex in rats. Behavioral Neuroscience, $111,712-726$.

Glover, G. H., \& Lai, S. (1998). Self-navigated spiral fMRI: Interleaved versus single-shot. Magnetic Resonance Imaging, 39, 361-368.

Gross, J. J. (1998). Antecedent- and response-focused emotion regulation: Divergent consequences for experience, expression, and physiology. Journal of Personality and Social Psychology, 74, 224-237.

Gross, J. J. (2002). Emotion regulation: Affective, cognitive, and social consequences. Psychophysiology, 9, 281-291.

Gross, J. J., \& John, O. P. (in press). Wise emotion regulation. In L. Feldman Barrett \& P. Salovey (Eds.), The wisdom of feelings: Psychological processes in emotional intelligence. New York: Guilford.

Gusnard, D. A., Akbudak, E., Shulman, G. L., \& Raichle, M. E. (2001). Medial prefrontal cortex and self-referential mental activity: Relation to a default mode of brain function. Proceedings of the National Academy of Sciences, U.S.A., 98, 4259-4264.

Hamann, S. B., Ely, T. D., Grafton, S. T., \& Kilts, C. D. (1999). Amygdala activity related to enhanced memory for pleasant and aversive stimuli. Nature Neuroscience, 2, 289-293.

Happe, F., Ehlers, S., Fletcher, P., Frith, U., Johansson, M., Gillberg, C., Dolan, R., Frackowiak, R., \& Frith, C. (1996). 'Theory of mind' in the brain. Evidence from a PET scan study of Asperger syndrome. NeuroReport, 8, 197-201.

Hariri, A. R., Bookheimer, S. Y., \& Mazziotta, J. C. (2000). Modulating emotional responses: Effects of a neocortical network on the limbic system. NeuroReport, 11, 43-48.

Holmes, A. P., \& Friston, K. J. (1998). Generalisability, random effects and population inference. Neuroimage: Abstracts of the Fourth International Conference on Functional Mapping of the Human Brain, 7, S754.

Hsieh, J. C., Stone-Elander, S., \& Ingvar, M. (1999). Anticipatory coping of pain expressed in the human anterior cingulate cortex: A positron emission tomography study. Neuroscience Letters, 262, 61-64.

Ito, T. A., Cacioppo, J. T., \& Lang, P. J. (1998). Eliciting affect using the International Affective Picture System: Trajectories through evaluative space. Personality and Social Psychology Bulletin, 24, 855-879.

Jackson, D. C., Malmstadt, J. R., Larson, C. L., \& Davidson, R. J. (2000). Suppression and enhancement of emotional responses to unpleasant pictures. Psychophysiology, 37, $515-522$.

Jonides, J., Smith, E. E., Marshuetz, C., Koeppe, R. A., \& Reuter-Lorenz, P. A. (1998). Inhibition in verbal working memory revealed by brain activation. Proceedings of the National Academy of Sciences, U.S.A., 95, 8410-8413.

Kawasaki, H., Kaufman, O., Damasio, H., Damasio, A. R., Granner, M., Bakken, H., Hori, T., Howard, M. A., III, \& Adolphs, R. (2001). Single-neuron responses to emotional visual stimuli recorded in human ventral prefrontal cortex. Nature Neuroscience, 4, 15-16.

Knight, R. T., Staines, W. R., Swick, D., \& Chao, L. L. (1999). Prefrontal cortex regulates inhibition and excitation in distributed neural networks. Acta Psychologica, 101, 159-178.

Kring, A. M., \& Gordon, A. H. (1998). Sex differences in emotion: Expression, experience, and physiology. Journal of Personality and Social Psychology, 74, 686-703.

Lane, R. (2000). Neural correlates of emotional experience. In R. D. Lane \& L. Nadel (Eds.), Cognitive Neuroscience of Emotion. New York: Oxford University Press.

Lane, R. D., Fink, G. R., Chau, P. M., \& Dolan, R. J. (1997). Neural activation during selective attention to subjective emotional responses. NeuroReport, 8, 3969-3972.

Lane, R. D., Reiman, E. M., Ahern, G. L., Schwartz, G. E., \& Davidson, R. J. (1997). Neuroanatomical correlates of happiness, sadness, and disgust. American Journal of Psychiatry, 154, 926-933.

Lane, R. D., Reiman, E. M., Bradley, M. M., Lang, P. J., Ahern, G. L., Davidson, R. J., \& Schwartz, G. E. (1997). Neuroanatomical correlates of pleasant and unpleasant emotion. Neuropsychologia, 35, 1437-1444.

Lang, P. J., Greenwald, M. K., Bradley, M. M., \& Hamm, A. O. (1993). Looking at pictures: Affective, visceral, and behavioral reactions. Psychophysiology, 30, 261-273.

Lazarus, R. S. (1991). Emotion and adaptation. New York: Oxford University Press.

LeDoux, J. E. (2000). Emotion circuits in the brain. Annual Review of Neuroscience, 23, 155-184.

Liberzon I., Taylor, S. F., Fig, L. M., Decker, L. R., Koeppe, R. A., \& Minoshima, S. (2000). Limbic activation and psychophysiologic responses to aversive visual stimuli. Interaction with cognitive task. Neuropsycho-

pharmacology, 23, 508-516.

MacDonald, A. W., Cohen, J. D., Stenger, V. A., \& Carter, C. S. (2000). Dissociating the role of the dorsolateral prefrontal and anterior cingulate cortex in cognitive control. Science, 288, 1835-1838.

Miller, E. K., \& Cohen, J. D. (2001). An integrative theory of prefrontal cortex function. Annual Review of Neuroscience, 24, 67-202.

Morgan, M. A., \& LeDoux, J. E. (1995). Differential contribution of dorsal and ventral medial prefrontal cortex to the acquisition and extinction of conditioned fear in rats. Behavioral Neuroscience, 109, 681-688.

Morris, J. S., Ohman, A., \& Dolan, R. J. (1999). A subcortical pathway to the right amygdala mediating "unseen" fear. Proceedings of the National Academy of Sciences, U.S.A., 96, 1680-1685.

Nielsen-Bohlman, L., \& Knight, R. T. (1999). Prefrontal cortical involvement in visual working memory. Brain Research. Cognitive Brain Research, 8, 299-310. 
Ochsner, K. N., \& Feldman Barrett, L. (2001). A multi-process perspective on the neuroscience of emotion. In G. Bonnano \& T. J. Mayne (Eds.), Emotion: Current issues and future directions (pp. 38-81). New York: Guilford.

Ochsner, K. N., \& Lieberman, M. D. (2001). The emergence of social cognitive neuroscience. American Psychologist, 56, 717-734.

Ochsner, K. N., \& Schacter, D. L. (in press). Remembering emotional events: A social cognitive neuroscience approach. In R. J. Davidson, H. Goldsmith, \& K. R. Scherer (Eds.), Handbook of the affective sciences. Oxford University Press: New York.

O'Doherty, J. O., Kringelbach, M. L., Rolls, E. T., Hornak, J., \& Andrews, C. (2001). Abstract reward and punishment representations in the human orbitofrontal cortex. Nature Neuroscience, 4, 95-102.

Paradiso, S., Jhonson, D. L., Andreasen, N. C., O'Leary, D. S., Watkins, G. L., Ponto, L. L., \& Hichwa, R. D. (1999). Cerebral blood flow changes associated with attribution of emotional valence to pleasant, unpleasant, and neutral visual stimuli in a PET study of normal subjects. American Journal of Psychiatry, 156, 1618-1629.

Peterson, B. S., Skudlarski, P., Gatenby, J. C., Zhang, H., Anderson, A. W., \& Gore, J. C. (1999). An fMRI study of Stroop word-color interference: Evidence for cingulate subregions subserving multiple distributed attentional systems. Biological Psychiatry, 45, 1237-1258.

Petit, L., Courtney, S. M., Ungerleider, L. G., \& Haxby, J. V. (1998). Sustained activity in the medial wall during working memory delays. Journal of Neuroscience, 18, 9429-9437.

Phelps, E. A., Hyder, F., Blamire, A. M., \& Shulman, R. G. (1997). FMRI of the prefrontal cortex during overt verbal fluency. NeuroReport, 8, 561-565.

Phelps, E. A., O'Connor, K. J., Gatenby, J. C., Gore, J. C., Grillon, C., \& Davis, M. (2001). Activation of the left amygdala to a cognitive representation of fear. Nature Neuroscience, 4, 437-441.

Ploghaus, A., Tracey, I., Gati, J. S., Clare, S., Menon, R. S., Matthews, P. M., \& Rawlins, J. N. (1999). Dissociating pain from its anticipation in the human brain. Science, 284, 1979-1981.

Quirk, G. J., Russo, G. K., Barron, J. L., \& Lebron, K. (2000). The role of ventromedial prefrontal cortex in the recovery of extinguished fear. Journal of Neuroscience, 20, 6225-6231.

Reiman, E. M., Lane, R. D., Ahern, G. L., Schwartz, G. E., Davidson, R. J., Friston, K. J., Yun, L. S., \& Chen, K. (1997). Neuroanatomical correlates of externally and internally generated human emotion. American Journal of Psychiatry, 154, 918-925.
Richards, J. M., \& Gross, J. J. (2000). Emotion regulation and memory: The cognitive costs of keeping one's cool. Journal of Personality and Social Psychology, 79, 410-424.

Rolls, E. T. (1999). The brain and emotion. New York: Oxford University Press.

Saxena, S., Brody, A. L., Maidment, K. M., Dunkin, J. J., Colgan, M., Alborzian, S., Phelps, M. E., \& Baxter, L. R., Jr. (1999). Localized orbitofrontal and subcortical metabolic changes and predictors of response to paroxetine treatment in obsessive-compulsive disorder. Neuropsychopharmacology, 21, 683-693.

Scherer, K. R., Schorr, A., \& Johnstone, T. (2001). Appraisal processes in emotion. New York: Oxford University Press.

Schoenbaum, G., Chiba, A. A., \& Gallagher, M. (1998). Orbitofrontal cortex and basolateral amygdala encode expected outcomes during learning. Nature Neuroscience, 1, 155-159.

Shakespeare, W. (1998/1623). The Oxford Shakespeare: Hamlet. New York: Oxford University Press.

Simpson, J. R., Ongur, D., Akbudak, E., Conturo, T. E., Ollinger, J. M., Snyder, A. Z., Gusnard, D. A., \& Raichle, M. E. (2000). The emotional modulation of cognitive processing: An fMRI study. Journal of Cognitive Neuroscience, 12, 157-170.

Smith, E., \& Jonides, J. (1999). Storage and executive processes in the frontal lobes. Science, 283, 657-660.

Stuss, D. T., Eskes, G. A., \& Foster, J. K. (1994). Experimental neuropsychological studies of frontal lobe functions. In $\mathrm{F}$. Boller \& J. Grafman (Eds.), Handbook of neuropsychology. Amsterdam: Elsevier.

van Veen, V., Cohen, J. D., Botvinick, M. M., Stenger, V. A., \& Carter, C. S. (2001). Anterior cingulate cortex, conflict monitoring, and levels of processing. Neuroimage, 14, $1302-1308$

Vuilleumier, P., Armony, J. L., Driver, J., \& Dolan, R. J. (2001). Effects of attention and emotion on face processing in the human brain: An event-related fMRI study. Neuron, 30, $829-841$.

Winston, J. S., Strange, B. A., O'Doherty, J., \& Dolan, R. J. (2002). Automatic and intentional brain responses during evaluation of trustworthiness of faces. Nature Neuroscience, 5, 277-283.

Whalen, P. J., Rauch, S. L., Etcoff, N. L., McInerney, S. C., Lee, M. B., \& Jenike, M. A. (1998). Masked presentations of emotional facial expressions modulate amygdala activity without explicit knowledge. Journal of Neuroscience, 181, $411-418$.

Zald, D. H., \& Pardo, J. V. (1997). Emotion, olfaction, and the human amygdala: Amygdala activation during aversive olfactory stimulation. Proceedings of the National Academy of Sciences, U.S.A., 94, 4119-4124. 